\title{
Denosumab - a new medication in the treatment of postmenopausal osteoporosis
}

\author{
Radosław Słopień ${ }^{1}$, Piotr Rynio ${ }^{2}$, Elżbieta Kubala ${ }^{3}$, Ewa Milewska ${ }^{1}$, Blazej Meczekalski ${ }^{1}$ \\ ${ }^{1}$ Department of Gynecological Endocrinology, Poznan University of Medical Sciences, Poznan, Poland \\ ${ }^{2}$ Department of Gynecology and Obstetrics, Stanisław Staszic Specialist Hospital in Piła, Poland \\ ${ }^{3}$ Department of Dental Physicodiagnostics and Propedeutics, Pomeranian Medical University in Szczecin, Poland
}

\begin{abstract}
Osteoporosis is a chronic, systemic skeletal disorder characterised by decreased bone density. It leads to an increased risk of bone fractures - one of the major causes of disability in modern societies. Bisphosphonates are the most commonly used medications in the treatment of postmenopausal osteoporosis. Denosumab, a new approach to fracture prevention, is a fully human monoclonal antibody that targets nuclear factor- $\mathrm{K} B$ ligand (RANKL), an important cytokine regulating formation and function of osteoclasts. Generally, denosumab is not used as initial therapy; however, in some cases it should be considered. It concerns patients at high risk of fracture, such as older patients who have difficulty with the dosing requirements of oral bisphosphonates or who have markedly impaired renal function. Denosumab can be also considered in patients who present intolerance or unresponsiveness to other therapies. Clinical studies have shown that denosumab is highly effective in increasing bone mineral density (BMD) in postmenopausal women regardless of the site analysed, as well as reducing the risk of bone fractures. The risk of developing antiresorptive, agent-induced osteonecrosis of the jaw related to denosumab therapy is low.
\end{abstract}

Key words: denosumab, osteoporosis, bone mineral density, fracture.

\section{Introduction}

Osteoporosis is a chronic, systemic skeletal disorder characterised by decreased bone density [1-3]. Diagnosis of osteoporosis, according to World Health Organisation guidelines, is bone mineral density (BMD) T-score equal to or lower than -2.5 [4]. Osteoporosis leads to an increased risk of bone fractures - one of the major causes of disability in modern societies $[1,2]$. In the year 2000 about 9 million of new bone fractures related to osteoporosis occurred worldwide [2]. The treatment of osteoporosis consists of the use of medications that prevent and reverse bone density loss.

The most commonly used medications in the treatment of postmenopausal osteoporosis are bisphosphonates [5-7]. Bisphosphonates decrease bone turnover by binding to mineralised surface of bone tissue and decreasing the resorbing activity of osteoclasts. This leads to an increase in bone mineral density and lowers the risk of fracture [8-16]. However, the dosing regimens of bisphosphonates are complicated, side effect numerous, and some of them are potentially difficult to treat (osteonecrosis of the jaw) [17]. This leads to poor adherence to therapy, increases costs therapy, and creates the need for new medications $[18,19]$.

\section{Denosumab: general data}

Denosumab, a new approach to fracture prevention, is a fully human monoclonal antibody that targets nuclear factor- $\kappa B$ ligand (RANKL), an important cytokine regulating formation and function of osteoclasts [3, 20-23]. By binding to RANKL, denosumab prevents its interaction with the receptor RANK located on surfaces of osteoclasts and their precursors. Denosumab affects osteoclasts at an earlier stage of their life than bisphosphonates, inactivating them before they adhere to the bone tissue [20-24]. This mechanism inhibits bone resorption [25]. Denosumab is injected subcutaneously (60 mg) every 6 months [26].

\section{Denosumab: for whom is this therapy?}

The decision about osteoporosis treatment should be individualised. Initial therapy is referred to lifestyle changes and oral bisphosphonates. Generally, denosumab is not used as initial therapy however in some cases it should be considered. It concerns patients at high risk of fracture, such as older patients who have difficulty with the dosing requirements of oral bisphosphonates or who 
have markedly impaired renal function [27]. Denosumab can be also considered in patients who present intolerance or unresponsiveness to other therapies [28]. This drug should not be used in premenopausal women and children. Numerous data suggest that postmenopausal women report greater satisfaction with denosumab, both overall and with its dosing frequency and route of administration and they would choose denosumab over bisphosphonates for long-term treatment [29]. At present it is important to personalise osteoporosis treatment taking patient preference into account, especially in regards to frequency and route of administration.

\section{Denosumab: results of clinical trials Denosumab and the risk of fractures}

In the FREEDOM study (Fracture Reduction Evaluation of Denosumab in Osteoporosis Every 6 Months) [30] 7808 postmenopausal women (between the ages of 60 and 90 years, T-score of less than -2.5 but not less than -4.0 at the lumbar spine or total hip) were randomised to receive denosumab (60 mg subcutaneous injections) or placebo every 6 months for 3 years. Denosumab reduced the risk of new radiographic vertebral fracture by $68 \%$ in comparison with placebo (cumulative incidence of $2.3 \%$ in the denosumab group, vs. $7.2 \%$ in the placebo group; risk ratio $0.32 ; 95 \% \mathrm{Cl}: 0.26-0.41 ; p<0.001)$. It also decreased the risk of hip fracture (a relative decrease of $40 \%$ ) and nonvertebral fracture (a relative decrease of $40 \%$ ). In women previously diagnosed with osteoporosis, subcutaneous denosumab injections (60 mg every 6 months for 36 months) resulted in reduction of risk of vertebral, nonvertebral, and hip fractures.

The patients who completed the 3 year FREEDOM study could enter the 7-year FREEDOM Extension Study [31]. In this study all subjects received denosumab, because placebo group was not continued for ethical reasons. In the FREEDOM Extension study a total of 4550 patients were registered. In the long term group 2343 subjects received denosumab for up to 8 years, and in the cross-over group 2207 subjects received denosumab for up to 5 years. In both groups, mean BMD values increased significantly. Cumulative 8 -year gains in the long term group were $18.4 \%$ at the lumbar spine and $8.3 \%$ at the total hip. Cumulative 5 -year gains in the cross-over group were $13.1 \%$ at the lumbar spine and $6.2 \%$ at the total hip. There were 2 events of atypical femoral fracture and 8 events of osteonecrosis of the jaw confirmed through year five.

\section{Denosumab comparison with bisphosphonates}

In the DECIDE study (The Determining Efficacy: Comparison of Initiating Denosumab versus Alen- dronate) denosumab was compared in a randomised double-blind prospective study with alendronate in 1189 postmenopausal women with low bone density (T-Score equal to or lower than -2.0) [32]. Denosumab 60 mg was injected subcutaneously every 6 months and alendronate was given orally $70 \mathrm{mg}$ every week. At the total hip, denosumab resulted in a statistically greater increase in bone mineral density in comparison with alendronate $(3.5 \%$ vs. $2.6 \%, p<0.0001)$. The greater increases in bone mineral density with subcutaneous denosumab were also found at all skeletal sites analyzed. Adverse effects and laboratory findings were similar for groups treated with alendronate and denosumab. The safety profile of both treatments was similar.

In the STAND study (Study of Transitioning from Alendronate to Denosumab) [33] a total of 504 postmenopausal women previously treated with alendronate for at least 6 months (median 36 months) were randomised in a double-blind prospective study to receive subcutaneous denosumab injections $60 \mathrm{mg}$ once every 6 months or to continue receiving oral alendronate $70 \mathrm{mg}$ every week. In patients transitioning to denosumab, total hip bone mineral density increased significantly compared to patients continuing receiving alendronate $(1.90 \%$ vs. $1.05 \% ; p<0.0001)$. The values of bone mineral density increased more significantly with subcutaneous denosumab compared with oral alendronate at 12 months at the lumbar spine, femoral neck, and $1 / 3$ radius (all $p<0.0125$ ). The safety profile of both groups was similar. The authors concluded that transition from alendronate to denosumab resulted in greater bone mineral density increases regardless of the site measured and a greater reduction in bone turnover.

Recknor et al. compared $60 \mathrm{mg}$ of denosumab given subcutaneously every 6 months (417 postmenopausal women) with $150 \mathrm{mg}$ of oral ibandronate given every month (416 postmenopausal women) for 12 months [34]. In the group receiving denosumab bone mineral density was significantly higher than in the group receiving ibandronate at the level of total hip (2.3\% vs. $1.1 \%$ ), femoral neck ( $1.7 \%$ vs. $0.7 \%$ ), and lumbar spine (4.1\% vs. 2.0\%; treatment difference 0.001 at all sites). The adverse event rates were similar in both groups: $59.6 \%$ in denosumab-treated subjects and $56.1 \%$ in ibandronate-treated subjects. Serious adverse event rate was $9.5 \%$ for the denosumab group and $5.4 \%$ for the ibandronate group. The authors concluded that denosumab injected every 6 months resulted in greater bone mineral density gains than ibandronate at all measured sites in postmenopausal women.

Roux et al. compared subcutaneous injections of denosumab (60 mg) every 6 months with oral risedronate (150 mg) every month for 1 year in a randomised study conducted in 870 postmenopausal women who had previously been prescribed alendronate therapy, but their adherence to treatment was suboptimal or they had 
stopped taking alendronate [35]. Denosumab injections significantly increased bone mineral density in comparison with risedronate at the total hip ( $2.0 \%$ vs. $0.5 \%)$, lumbar spine (3.4\% vs. $1.1 \%)$ and femoral neck (1.4\% vs. $0 \%$; $p<0.0001$ at all sites). Adverse events, both overall and serious, were similar regardless of the group analysed. The authors concluded that in postmenopausal women with suboptimal adherence to therapy with alendronate, subcutaneous denosumab was more effective than oral risedronate in improving bone mineral density values.

\section{Antiresorptive agent-induced osteonecrosis of the jaw}

In 2010 Aghaloo et al. described a case of osteonecrosis of the jaw in a patient who received injections of denosumab [36]. Moreover, not only bisphosphonates and denosumab, but also other bone modulating and anti-angiogenic agents and, e.g. cathepsin K inhibitors, tyrosine kinase inhibitors, and bevacizumab possess suspected or proven potential to trigger the ONJ development [37]. Because of this, American Dental Association (ADA) proposed the term "antiresorptive agent-induced osteonecrosis of the jaw" for all cases of related to use of antiresorptive agents [38]. Extended drug use increases the risk of developing osteonecrosis of the jaw. Nevertheless, it appears to be low in a patient who does not have cancer. In a large sample of patients with oral bisphosphonate exposure its highest prevalence was estimated to be about $0.1 \%$ [39]. In the FREEDOM Extension study the risk of osteonecrosis of the jaw in patients exposed to denosumab was 4.2 per 10,000 subject-years (0.042\%) [38]. According to American Dental Association (ADA) an optimal approach for lowering the risk of developing this condition may be an oral health program consisting of sound oral hygiene practices and regular dental care [38].

\section{Conclusions}

Low bone mineral density (BMD) is a pharmacologically modifiable risk factor for bone fracture in postmenopausal women [40]. Data acquired clinical studies showed that denosumab is highly effective in increasing bone mineral density (BMD) in postmenopausal women regardless of the site analysed as well as reducing the risk of bone fractures. Denosumab compared to different bisphosphonates (alendronate, ibandronate, risedronate) was more efficient in increasing BMD. Unlike other antiresorptive agents [40,41], denosumab induced BMD gain does not reach plateau after 2 to 4 years of treatment [42]. Dosing regimen of denosumab is uncomplicated and adverse events rate not higher than other antiresorptive agents. About $50 \%$ of patients stop taking prescribed osteoporosis medication during the first year of therapy and therefore may benefit from switching to a different medication $[43,44]$. The risk of bone fractures is higher in patients who do not adhere optimally to the prescribed osteoporosis pharmacotherapy [19, 45-47]. Optimal adherence to the therapy can be ensured for 6 months by subcutaneous injections of denosumab given twice a year. The risk of developing antiresorptive agent-induced osteonecrosis of the jaw related to denosumab therapy is low. The risk can be reduced by oral examination before treatment, as well as proper hygiene practices and further routine dental examinations.

\section{Disclosure}

Authors report no conflict of interest.

\section{References}

1. Cummings SR, Melton LJ. Epidemiology and outcomes of osteoporotic fractures. Lancet 2002; 359: 1761-1767.

2. Johnell O, Kanis JA. An estimate of the worldwide prevalence and disability associated with osteoporotic fractures. Osteoporos Int 2006; 17 : 1726-1733.

3. Boyle WJ, Simonet WS, Lacey DL. Osteoclast differentiation and activation. Nature 2003; 423: 337-342.

4. WHO Scientific Group on the Prevention and Management of Osteoporosis (2000: Geneva, Switzerland) (2003). Prevention and management of osteoporosis: report of a WHO scientific group.

5. Huot L, Couris CM, Tainturier V, et al. Trends in HRT and anti-osteoporosis medication prescribing in a European population after the WHI study. Osteoporos Int 2008; 19: 1047-1054.

6. Stafford RS, Drieling RL, Hersh AL. National trends in osteoporosis visits and osteoporosis treatment, 1988-2003. Arch Intern Med 2004; 164: 1525-1530.

7. Watson J, Wise L, Green J. Prescribing of hormone therapy for menopause, tibolone, and bisphosphonates in women in the UK between 1991 and 2005. Eur J Clin Pharmacol 2007; 63: 843-849.

8. Black DM, Delmas PD, Eastell R, et al. Once-yearly zoledronic acid for treatment of postmenopausal osteoporosis. N Engl J Med 2007; 356: 1809-1822.

9. Black DM, Thompson DE, Bauer DC, et al. Fracture risk reduction with alendronate in women with osteoporosis: The Fracture Intervention Trial. FIT Research Group. J Clin Endocrinol Metab 2000; 85: 4118-4124.

10. Boonen S, McClung MR, Eastell R, et al. Safety and efficacy of risedronate in reducing fracture risk in osteoporotic women aged 80 and older: Implications for the use of antiresorptive agents in the old and oldest old. J Am Geriatr Soc 2004; 52: 1832-1839.

11. Cummings SR, Black DM, Thompson DE, et al. Effect of alendronate on risk of fracture in women with low bone density but without vertebral fractures: Results from the Fracture Intervention Trial. JAMA 1998; 280: 2077-2082.

12. Harris ST, Blumentals WA, Miller PD. Ibandronate and the risk of nonvertebral and clinical fractures in women with postmenopausal osteoporosis: Results of a meta-analysis of phase III studies. Curr Med Res Opin 2008; 24: 237-245.

13. Harris ST, Watts NB, Genant HK, et al. Effects of risedronate treatment on vertebral and nonvertebral fractures in women with postmenopausal osteoporosis: A randomized controlled trial. Vertebral Efficacy With Risedronate Therapy (VERT) Study Group. JAMA 1999; 282: 1344-1352.

14. Kanis JA, Barton IP, Johnell O. Risedronate decreases fracture risk in patients selected solely on the basis of prior vertebral fracture. Osteoporos Int 2005; 16: 475-482.

15. Siris ES, Simon JA, Barton IP, et al. Effects of risedronate on fracture risk in postmenopausal women with osteopenia. Osteoporos Int 2008; 19 : 681-686. 
16. Watts NB, Josse RG, Hamdy RC, et al. Risedronate prevents new vertebral fractures in postmenopausal women at high risk. J Clin Endocrinol Metab 2003; 88: 542-549.

17. Sambrook P, Cooper C. Osteoporosis. Lancet 2006; 367: 2010-2018.

18. Recker RR, Gallagher R, MacCosbe PE. Effect of dosing frequency on bisphosphonate medication adherence in a large longitudinal cohort of women. Mayo Clin Proc 2005; 80: 856-861.

19. Siris ES, Harris ST, Rosen CJ, et al. Adherence to bisphosphonate therapy and fracture rates in osteoporotic women: relationship to vertebral and nonvertebral fractures from 2 US claims databases. Mayo Clin Proc 2006; 81: 1013-1022.

20. Lacey DL, Tan HL, Lu J, et al. Osteoprotegerin ligand modulates murine osteoclast survival in vitro and in vivo. Am J Pathol 2000; 157: 435-448.

21. Lacey DL, Timms E, Tan HL, et al. Osteoprotegerin ligand is a cytokine that regulates osteoclast differentiation and activation. Cell 1998; 93: 165-176.

22. Udagawa N, Takahashi N, Yasuda H, et al. Osteoprotegerin produced by osteoblasts is an important regulator in osteoclast development and function. Endocrinology 2000; 141: 3478-3484.

23. Yasuda H, Shima N, Nakagawa N, et al. Osteoclast differentiation factor is a ligand for osteoprotegerin/osteoclastogenesis-inhibitory factor and is identical to TRANCE/RANKL. Proc Natl Acad Sci USA 1998; 95 3597-3602.

24. Burgess TL, Qian Y, Kaufman S. The ligand for osteoprotegerin (OPGL) directly activates mature osteoclasts. J Cell Biol 1999; 145: 527-538.

25. Delmas PD. Clinical potential of RANKL inhibition for the management of postmenopausal osteoporosis and other metabolic bone diseases. J Clin Densitom 2008; 11: 325-338

26. Cummings SR, San Martin J, McClung MR, et al. Denosumab for prevention of fractures in postmenopausal women with osteoporosis. N Engl J Med 2009; 361: 756-765.

27. Herrero S, Pico Y. Treatments for post-menopausal osteoporotic women, what's new? How can we manage long-term treatment? Eur J Pharmacol 2016; 779: 8-21.

28. Cairoli E, Eller-Vainicher C, Chiodini I. Update on denosumab in the management of postmenopausal osteoporosis: patient preference and adherence. Int J Womens Health 2015; 7: 833-839.

29. Kendler DL, Bessette L, Hill CD, et al. Preference and satisfaction with a 6-month subcutaneous injection versus a weekly tablet for treatment of low bone mass. Osteoporos Int 2010; 21: 837-846.

30. Cummings SR, San Martin J, McClung MR, et al. Denosumab for prevention of fractures in postmenopausal women with osteoporosis. FREEDOM Trial. N Engl J Med 2009; 361: 756-765.

31. The effect of 8 or 5 years of denosumab treatment in postmenopausal women with osteoporosis: results from the FREEDOM Extension study. Osteoporos Int 2015; 26: 2773-2783.

32. Brown JP, Prince RL, Deal C, et al. Comparison of the effect of denosum$\mathrm{ab}$ and alendronate on BMD and biochemical markers of bone turnover in postmenopausal women with low bone mass: a randomized, blinded, phase 3 trial. J Bone Miner Res 2009; 24: 153-161.

33. Kendler DL, Roux C, Benhamou CL, et al. Effects of denosumab on bone mineral density and bone turnover in postmenopausal women transitioning from alendronate therapy. J Bone Miner Res 2010; 25: 72-81.

34. Recknor C, Czerwinski E, Bone HG, et al. Denosumab compared with ibandronate in postmenopausal women previously treated with bisphosphonate therapy: a randomized open-label trial. Obstet Gynecol 2013; 121: 1291-1299.

35. Roux C, Hofbauer LC, Ho PR, et al. Denosumab compared with risedronate in postmenopausal women suboptimally adherent to alendronate therapy: efficacy and safety results from a randomized openlabel study. Bone 2014; 58: 48-54.

36. Aghaloo TL, Felsenfeld AL, Tetradis S. Osteonecrosis of the jaw in a patient on Denosumab. J Oral Maxillofac Surg 2010; 68: 959-963.

37. Patel V, Kelleher M, Sproat C, et al. New cancer therapies and jaw necrosis. British Dental Journal 2015; 219: 203-207.

38. Managing the care of patients receiving antiresorptive therapy for prevention and treatment of osteoporosis. Executive summary of recommendations from the American Dental Association Council on Scientific Affairs. JADA 2011; 142: 1243-1251.

39. Lo JC, O'Ryan FS, Gordon NP. Predicting Risk of Osteonecrosis of the Jaw with Oral Bisphosphonate Exposure (PROBE) Investigators. Prevalence of osteonecrosis of the jaw in patients with oral bisphosphonate exposure. J Oral Maxillofac Surg 2010; 68: 243-253.

40. Austin M, Yang YC, Vittinghoff E, et al. Relationship between bone mineral density changes with denosumab treatment and risk reduction for vertebral and nonvertebral fractures. J Bone Miner Res 2012; 27: 687693.

41. Black DM, Schwartz AV, Ensrud KE, et al. Effects of continuing or stopping alendronate after 5 years of treatment: the Fracture Intervention Trial Long-term Extension (FLEX): a randomized trial. JAMA 2006; 296: 2927-2938.

42. Black DM, Reid IR, Boonen S, et al. The effect of 3 versus 6 years of zoledronic acid treatment of osteoporosis: a randomized extension to the HORIZON-Pivotal Fracture Trial (PFT). J Bone Miner Res 2012; 27: 243-254.

43. Silverman SL, Gold DT. Compliance and persistence with osteoporosis therapies. Curr Rheumatol Rep 2008; 10: 118-122.

44. Yeaw J, Benner JS, Walt JG, et al. Comparing adherence and persistence across 6 chronic medication classes. J Manag Care Pharm 2009; 15: 728-740.

45. Caro JJ, Ishak KJ, Huybrechts KF, et al. The impact of compliance with osteoporosis therapy on fracture rates in actual practice. Osteoporos Int 2004; 15: 1003-1008.

46. Huybrechts KF, Ishak KJ, Caro JJ. Assessment of compliance with osteoporosis treatment and its consequences in a managed care population. Bone 2006; 38: 922-928.

47. Weycker D, Macarios D, Edelsberg J, Oster G. Compliance with osteoporosis drug therapy and risk of fracture. Osteoporos Int 2007; 18: 271 277. 